\title{
GESTÃO DA INFORMAÇÃO E DO CONHECIMENTO: ORIGENS, POLÊMICAS E PERSPECTIVAS
}

\author{
GESTIÓN DE INFORMACIÓN Y DEL CONOCIMIENTO: \\ ORIGEN, POLÉMICAS Y PERSPECTIVAS
}

\begin{abstract}
Ricardo Rodrigues Barbosa - ricardobarbosa@ufmg.br
Pós-doutor pela Faculty of Information Studies da University of Toronto. Doutor em Administração pela Columbia University. Professor titular da Escola de Ciência da Informação da UFMG.
\end{abstract}

\section{Resumo}

O artigo apresenta e discute os conceitos e a importância da informação e do conhecimento no contexto empresarial. Compara a gestão da informação e a gestão do conhecimento, e os aspectos relacionados com a origem e a evolução destas disciplinas. Evidencia o uso da tecnologia da informação e seu valor para a gestão da informação e do conhecimento. Aborda os meandros de sustentação e os preceitos da gestão do conhecimento e ressalta que mais do que um modismo ela é uma temática que está se consolidando em pesquisas e publicações científicas. Conclui que a informação e o conhecimento são fenômenos indissociáveis e complementares da vida organizacional, e que as inovações tecnológicas das áreas de computação e de telecomunicações contribuem para o compartilhamento de informação e conhecimento nas organizações.

\section{Palavras-chave}

Gestão da informação; Gestão do conhecimento; Tecnologias de informação; Conhecimento organizacional. 


\section{INTRODUÇÃO}

As expressões gestão da informação (GI) e gestão do conhecimento (GC) constituem dois componentes de uma constelação de termos relacionados. Dentre esses, destacam-se documentação, gerência de recursos informacionais, organização do conhecimento, biblioteconomia, organização aprendente, gestão de documentos, organização da informação, arquivologia, ciência da informação, conhecimento tácito, conhecimento explícito, representação do conhecimento, aprendizagem organizacional, inteligência organizacional, organização inteligente, gestão do saber, dentre outros. Essa verdadeira babel terminológica, se por um lado reflete o grande interesse que a informação e o conhecimento despertam atualmente na sociedade, por outro constitui um grande desafio no sentido de se distinguir um conceito dos demais e de se estabelecer relacionamentos entre eles.

Devido à sua crescente importância para as organizações contemporâneas, a informação e o conhecimento têm merecido, cada vez mais, a atenção de gestores, profissionais e pesquisadores. O contínuo desenvolvimento das tecnologias da informação e da comunicação (TICs) tem potencializado a produção e a disseminação de informações em escalas inimagináveis há pouco tempo atrás. É inegável que as redes de comunicação, que hoje em dia integram não apenas computadores pessoais, mas também telefones celulares e diversos outros aparelhos, têm sido incorporados, de forma irreversível, nos mais diversos aspectos dos afazeres humanos. Do lado da demanda, tanto para as pessoas quanto para as organizações, a obtenção e uso da informação tornam-se, cada vez mais, processos críticos para o seu desempenho.

À medida que os ambientes profissionais e de negócios se tornam mais complexos e mutantes, a informação se transforma, indiscutivelmente, em uma arma capaz de garantir a devida antecipação e análise de tendências, bem como a capacidade de adaptação, de aprendizagem e de inovação. Este é o conhecimento que Mokyr (2002) chama de conhecimento útil, o qual consiste em dois elementos. O primeiro é o conhecimento "que", ou conhecimento proposicional, constituído de crenças a respeito dos fenômenos e regularidades do nosso mundo natural. Uma vez possuído, o conhecimento "que" pode produzir o conhecimento "como", ou seja, o conhecimento instrucional ou prescritivo, o qual pode ser chamado de técnicas. É esse tipo de conhecimento - o conhecimento útil - que é objeto de estudos da comunidade acadêmica e elemento motivador dos esforços de gerenciamento em con- 
textos organizacionais, seja em empresas, em entidades públicas ou em organizações do terceiro setor.

A revolução dos computadores e das telecomunicações tem provocado inúmeros debates a respeito de seus efeitos nas organizações e na sociedade como um todo. Acredita-se que uma forma de se avaliar a importância desse fenômeno é verificar em que medida ele tem provocado o interesse de pensadores e pesquisadores. Com esse objetivo, em setembro de 2007, foram realizadas buscas no Google Scholar no sentido de se detectar quantos documentos contêm as palavras information e management em seus títulos. No total, foram encontrados cerca de 46000 oriundos das áreas de administração, negócios, finanças e economia. Quando o argumento de busca é knowledge e management, são encontrados cerca de 34400 documentos. Trata-se, portanto, de uma produção acadêmica respeitável. A importância da informação e do conhecimento para as pessoas e para as organizações pode ser estimada também, por exemplo, pelo número de periódicos dedicados ao assunto. Nesse sentido, um levantamento, feito por este autor no Portal Capes de periódicos, constatou que, dos 11419 periódicos disponíveis em setembro de 2007, 222 tinham as palavras information, informação ou knowledge em seus títulos. Esta pode ser consi- derada uma quantidade expressiva de periódicos, pois corresponde a quase $2 \%$ do total de títulos de um acervo que cobre praticamente todas as áreas do conhecimento humano.

A importância da informação e do conhecimento para as organizações também tem sido registrada por autores do campo da economia, das finanças e da contabilidade. Por exemplo, Harris (2001) identifica o conceito de "economia baseada no conhecimento" como sendo um referencial analítico capaz de incorporar as características centrais das novas tecnologias da informação e da comunicação. Também o conceito de "economia da informação", conforme esse autor, representa a noção de que o conhecimento pode ser aplicado inúmeras vezes sem perder valor com o uso repetido, é infinitamente durável no tempo e no espaço, além de poder ser armazenado com custo mínimo nos meios digitais contemporâneos.

O conceito de sociedade do conhecimento pode ser interpretado sob mais de uma perspectiva. A mais antiga dessas, conforme Powell e Snellman (2004), tem a origem nos trabalhos dos economistas Fritz Machlup e Marc Uri Porat e do sociólogo Daniel Bell, os quais destacam, dentre outros aspectos, a introdução de inovações tecnológicas e seu papel no desenvolvimen- 
to econômico e nas transformações sociais. Enquanto os enfoques dos autores acima mencionados são mais abrangentes, um outro grupo de autores, dentre os quais se destacam Peter Drucker, Ikujiro Nonaka, Hirotaka Takeuchi, Thomas Stewart, Thomas Davenport, e Larry Prusak, procuram focalizar a questão do conhecimento dentro de contextos organizacionais. Em seu conjunto, a mensagem desses autores é clara: a informação e o conhecimento se transformam, cada vez mais, em importantes fatores de transformações econômicas e sociais. De fato, conforme Drucker (1969, p. 264), “[...] o conhecimento é hoje o custo mais elevado, o principal investimento e o principal produto da economia avançada, bem como o meio de vida do maior grupo da população".

Em decorrência de seu significado econômico e de sua importância social, os resultados dos investimentos em tecnologia da informação ( $\mathrm{TI})$ nas organizações têm sido investigado por inúmeros autores. Esses estudos, no entanto, têm produzido indicações contraditórias a respeito dos reais impactos organizacionais. O economista Robert Solow, ganhador do Prêmio Nobel de Economia e professor do MIT comentou, em 1987, que o computador estava em toda parte, menos nas estatísticas de produtividade. Essa afirmativa provocou um grande debate, ainda hoje aceso, a respeito da contribuição da TI para o desempenho das empresas e, em última análise, para a economia como um todo.

Não obstante as incertezas e riscos relacionados com os investimentos nas TICs, as empresas têm investido cada vez mais nessa área. Dados da empresa de consultoria Forrester Research, divulgados pelo Instituto de Desenvolvimento Global - IDG Brasil (IDG NOW, 2006), estimam que os investimentos em Tl, em termos mundiais, alcançarão mais de um trilhão e meio de dólares em 2007. Isto significa um acréscimo de $5 \%$ em relação aos dados do ano anterior. Considerando-se que o crescimento mundial desses investimentos foi de $8 \%$ tanto em 2005 quanto em 2006, estima-se que a taxa média de crescimento no triênio que inclui 2007 tenha sido de aproximadamente $7 \%$. Ao se agregarem os gastos com os recursos humanos, esse montante alcança a cifra de 2,23 trilhões de dólares. Se os dados a respeito dos investimentos globais em TI são impressionantes, no Brasil, guardadas as devidas proporções, a situação não é diferente. Conforme dados do Ministério do Desenvolvimento Indústria e Comércio Exterior (BRASIL, 2007), o Brasil deverá encerrar o ano de 2007 com um orçamento de TI na ordem de $R \$ 45$ bilhões. Esta cifra corresponde a um aumento da participação relativa 
da TI dentro do PIB nacional, que passou de $2 \%$ em 2006 para $2,2 \%$ no presente ano.

Os valores acima demonstram o quanto as infra-estruturas de $\mathrm{TI}$ - as quais envolvem não apenas máquinas e equipamentos, mas também pessoal especializado - têm representado, do ponto de vista orçamentário, para as nações e para as organizações. No entanto, todo esse gasto não produz apenas resultados positivos. De fato, ao lado dos visíveis benefícios proporcionados pelo desenvolvimento das TICs, existem também diversos problemas que, quando não devidamente equacionados, podem levar a graves conseqüências, tanto no plano pessoal quanto no nível organizacional. Para as pessoas, há os problemas relacionados com sobrecarga e stress informacionais, bem como as questões relativas à segurança, invasão de privacidade, propriedade intelectual, dentre outros. Já, para as empresas, os investimentos em $\mathrm{TI}$ envolvem riscos e são, muitas vezes, frustrantes do ponto de vista de seu retorno financeiro. Isto ocorre, dentre outros fatores, porque a influência da TI no resultado das empresas é moderada por diversos fatores, tais como a suas opções estratégicas (SHIN, 2001), bem como as suas estruturas e processos (HENDERSON; VENKATRAMAN, 1999).
Não é de se admirar o grande debate a respeito do uso da informação e do conhecimento em ambientes organizacionais. Os investimentos que são feitos no sentido de se capacitar as empresas com as mais modernas tecnologias de informação e de comunicações são, como se demonstrou acima, muito expressivos. Esses investimentos, por envolverem grandes volumes de recursos, demandam análises complexas por parte das cúpulas decisórias das empresas, as quais almejam as melhores relações custobenefício possíveis. A dificuldade, nesse caso, é que, enquanto os gastos são palpáveis, os benefícios são incertos. $E$, além da questão estritamente relacionada com os investimentos em si, o próprio percurso da informação e do conhecimento em um contexto organizacional é permeado de meandros.

Considerando-se os aspectos acima apontados, este artigo pretende, inicialmente, resgatar alguns aspectos relacionados com origem da gestão da informação e da gestão do conhecimento (GIC). Será feita também uma breve comparação entre essas duas disciplinas. Em seguida, será apresentado um modelo de gestão estratégica da gestão da informação e do conhecimento em contextos organizacionais. Finalmente, serão exploradas algumas possibilidades de desenvolvimento da GIC em decorrência do 
desenvolvimento das mais recentes tecnologias de colaboração em rede.

\section{AS ORIGENS}

A origem da moderna gestão da informação pode ser encontrada nos trabalhos de Paul Otlet, cujo livro Traité de documentation, publicado em 1934, foi um marco fundamental do desenvolvimento da gestão da informação, disciplina que, na época, era conhecida como documentação. De fato, muito do que hoje conhecemos modernamente por gerência de recursos informacionais tem suas origens nos trabalhos de Otlet. Por exemplo, Rayward (1991, p. 137) argumenta que "[...] para Otlet, o documento é o centro de um processo de comunicação complexo, da acumulação e transmissão do conhecimento, da criação e evolução das instituições". Pode-se verificar, portanto, que a preocupação com a informação e com o conhecimento enquanto fenômenos expressivos do ponto de vista gerencial e econômico, é muito mais antiga do que normalmente se pensa.

Além de Otlet, dois autores que se destacaram como precursores da moderna gestão da informação e do conhecimento são Vanevar Bush e Frederick Hayek. Esse autores publicaram, em 1945, dois importantes trabalhos. Bush, em artigo intitulado As we may think, concebeu uma máquina, por ele chamada Memex,

[...] na qual um indivíduo armazena todos os seus livros, registros e comunicações, e que é mecanizada de forma a poder ser consultada com grande velocidade e flexibilidade. É um suplemento ampliado e íntimo de sua memória (BUSH, 1945, p. 107).

O Memex nunca chegou a ser construído, mas é considerado hoje um precursor da Web e da moderna gestão eletrônica de documentos.

O economista Frederick Hayek, laureado com o Prêmio Nobel de economia em 1974, publicou um artigo intitulado The use of knowledge in society. Nesse texto, o autor argumenta que o problema econômico enfrentado pela sociedade encontra-se no fato de que o conhecimento nunca se encontra em forma "[...] concentrada ou integrada, mas apenas na forma de pedaços dispersos de conhecimento incompleto e freqüentemente contraditório que todos os indivíduos possuem separadamente" (HAYEK, 1945, p.

1). Ou seja, esse problema diz respeito a

[...] como garantir o melhor uso dos recursos conhecidos por cada um dos membros da sociedade, para fins cuja importância relativa apenas esses indivíduos conhecem. Ou, simplesmente, é o problema da utilização do conhecimento não possuído por ninguém em sua totalidade (HAYEK, 1945, p. 2). 
Observa-se, portanto, que, mesmo antes da disseminação dos computadores na sociedade, autores como Otlet, Bush e Hayek já se preocupavam com a informação e o conhecimento enquanto fenômenos relevantes do ponto de vista da produtividade pessoal e empresarial e, portanto, merecedores de esforços no sentido de seu efetivo gerenciamento.

Ainda dentro do espírito de se resgatar as origens da GIC, descobre-se que a expressão gestão do conhecimento é mais antiga do que normalmente se acredita. De fato, em artigo publicado na Public Administration Review, em 1974, Nicholas Henry definia gestão do conhecimento como "[...] políticas públicas para a produção, disseminação, acessibilidade e uso da informação na formulação de políticas públicas" (HENRY, 1974, p. 189). Já nessa época, o autor se preocupava com o que ele chamava "disfunções informacionais". A primeira dessas disfunções é o excesso de dados, fenômeno que, para o autor, pode provocar ruídos no processo decisório. A segunda disfunção diz respeito às próprias tecnologias da informação, em especial os sistemas de armazenamento e recuperação da informação baseados em computador, que são projetados para "[...] maximizar o conhecimento dos decisores e minimizar dados, os quais apenas turvam o foco e dispersa o impacto da for- mulação e o resultado das políticas públicas" (p. 191). Nota-se que as observações de Henry, embora contextualizada no campo da administração pública, podem perfeitamente se adequar às empresas contemporâneas. Outro trabalho, ao qual este autor teve acesso apenas na forma de seu abstract, é o de Berry e Cook (1976), cujo título, Managing knowledge as a corporate resource, bem reflete as preocupações atuais com a questão. Nesse documento, editado pelo Departamento de Defesa do Governo Americano, os autores discutem a relevância do conhecimento - e não dos dados e da informação - como recurso fundamental para as empresas.

O conceito de gerência de recursos informacionais (GRI), originalmente sugerido por Robert S. Taylor na década de 1960, ganhou notoriedade com a implantação do Paperwork Reduction Act, do Governo Americano, em 1980. A GRI apóia-se em três disciplinas essenciais, que são a administração, a computação e a ciência da informação $(\mathrm{Cl})$. No campo da $\mathrm{Cl}$, destacam-se a biblioteconomia, a gestão de documentos e a arquivologia (BERGERON, 1996).

De acordo com Savic (1992), o primeiro documento inteiramente dedicado à GRI é o livro de Forest Woody Horton Junior, How to harness information resources: a systems 
approach, publicado em 1974. Para esse autor, o termo "recursos informacionais" pode ser subdividido em três categorias: a) fontes de informação, b) serviços de informação, produtos de informação e c) sistemas de informação. Para ele, "uma fonte de informação é um indivíduo ou uma organização - um local - que fornece dados e informações necessárias para usuários" (HORTON JUNIOR, 1979, p. 90). Note-se que, para Horton Junior, uma pessoa pode ser considerada uma fonte de informação, o que é perfeitamente compatível com a noção dos colégios invisíveis no contexto da comunicação científica (MOREIRA, 2005; SARACEVIC, 1999), a qual pode ser considerada uma versão anterior do moderno conceito de comunidades de prática no contexto da gestão do conhecimento.

A gestão da informação, que tem sua origem na documentação, é uma disciplina mais consolidada do que a gestão do conhecimento, a qual começou a despertar o interesse da comunidade acadêmica e gerencial a partir do final da década de 1980. Para Prusak (2001, p. 1002), a gestão do conhecimento é a combinação de idéias novas e tradicionais e constitui uma resposta concreta à globalização, à disseminação dos computadores e a visão da empresa com base no conhecimento. A propósito da primeira tendência, esse autor argumenta que
"[...] a combinação do alcance global e velocidade força as organizações a se perguntarem: o que sabemos, quem sabe o quê, o que não sabemos mas precisamos saber?" Quanto à ubiqüidade dos computadores, Prusak afirma que esse fenômeno valoriza, por contraste, o conhecimento que não pode ser facilmente registrado, codificado ou disseminado. Para esse autor,

À medida que o acesso à informação se expande dramaticamente, de forma que as pessoas possam ter acesso a quase toda a informação de que elas necessitam a qualquer hora e em qualquer lugar, o valor das habilidades cognitivas ainda não replicadas pelo silício aumenta (PRUSAK, 2001, p. 1002).

A visão da empresa com base no conhecimento tem sido adotada, implícita ou explicitamente, por diversos teóricos do campo da administração e da economia. Em sua releitura das contribuições de Chester Barnard para o pensamento administrativo à luz da perspectiva da empresa baseada no conhecimento, Gehani (2002) aponta que Barnard já reconhecia a existência de dois tipos de conhecimento. O primeiro é constituído do conhecimento teórico, organizado e formal, o qual se obtém pela educação. $O$ outro, o conhecimento não registrado e intuitivo é, para ele, essencial para o desempenho das funções gerenciais. Ainda nesta linha, mas com um enfoque econômico, Grant 
(1996, p. 112) afirma que "[...] as empresas existem como instituições para produzir bens e serviços porque elas podem criar condições sob as quais múltiplos indivíduos podem integrar os seus conhecimentos especializados".

Como se pode verificar, tanto a gestão da informação quanto a gestão do conhecimento surgiram das contribuições de pensadores que viveram muito antes da introdução dos computadores e da recente explosão informacional. Um dos autores contemporâneos que popularizaram a gestão do conhecimento é, sem dúvida, Thomas Davenport. Alguns de seus livros, publicados no Brasil com os títulos Ecologia da Informação e Conhecimento Empresarial (o primeiro com a colaboração e o segundo em co-autoria com Larry Prusak), podem ser consideradas contribuições expressivas no sentido de se divulgar a GIC em contextos empresariais. Algumas idéias centrais dessas obras são que $\mathrm{o}$ investimento em tecnologias por si não é o suficiente para se garantir uma administração informacional eficiente e que os administradores precisam desenvolver uma perspectiva holística e integrada da informação. Esses autores desenvolveram ainda um "modelo ecológico" para o gerenciamento da informação, no qual se destaca o ambiente informacional, que é constituído pelos seguintes elementos: a) estratégia da informa- ção, que deriva do que a empresa deseja fazer com a informação; b) política (ou "sistema político") da informação; c) a cultura e o comportamento em relação à informação, d) a equipe de informação; e) os processos de administração informacional e f) a arquitetura da informação, que para ele é simplesmente um "[...] guia para estruturar e localizar a informação dentro de uma organização" (DAVENPORT, 1997, p. 54).

A produção intelectual relativa à gestão da informação e do conhecimento constitui o esforço de diversos campos. Dentre eles, destacam-se a administração, a computação e a ciência da computação. E, como não se poderia evitar, há muitas divergências conceituais entre os autores, seja entre as áreas e mesmo dentro delas. Essas divergências foram analisadas por Elizabeth Davenport e Blaise Cronin (2000), que identificam três visões distintas da gestão do conhecimento. A primeira, denominada por eles de GC1 tem suas bases na biblioteconomia e na ciência da informação. Aqui, a gestão do conhecimento é vista por muitos simplesmente como um produto velho em nova embalagem. Ou seja, a gestão do conhecimento não passa de gestão da informação com outro nome.

A GC2 identifica a gestão do conhecimento com a gestão do know-how e prioriza 
processos e atividades organizacionais, com ênfase nas representações (ontologias) dessas atividades e capacidades. Essa perspectiva, fortemente orientada para sistemas, enfatiza a extração e o descobrimento do valor contido em repositórios de dados e de informação por meio de técnicas sofisticadas, tais como data mining e data warehouse. A propósito da perspectiva de sistemas da gestão do conhecimento, deve-se salientar que, no campo da inteligência artificial, os sistemas especialistas são também conhecidos como sistemas baseados em conhecimento (knowledge based systems). Nesse contexto, os conceitos de representação do conhecimento, engenharia do conhecimento, bases de conhecimento, são bem estabelecidos.

Por último, a GC3 tem seus fundamentos na teoria organizacional e considera o conhecimento como fator capaz de proporcionar a adaptação da empresa ao seu ambiente externo. Aqui, o aspecto central da GC é o relacionamento entre o conhecimento tácito e o conhecimento explícito. $\mathrm{O}$ conceito de "ba", ou o contexto onde o "conhecer" acontece, é um dos conceitos centrais na GC3. Neste caso, o que é gerenciado não é o conhecimento em si, e sim o contexto no qual ele se manifesta.
Essas diversas e às vezes contraditórias visões a respeito da informação e do conhecimento suscitam questões a respeito das possibilidades de seu gerenciamento em contextos organizacionais. Para muitos autores, o conhecimento, na melhor das hipóteses pode ser gerenciado apenas pelo seu possuidor. Para outros, o conhecimento pode ser gerenciado, ainda que indiretamente, por meio da manipulação das condições que cercam a sua produção e uso. Estas questões serão analisadas a seguir.

\section{O CONHECIMENTO PODE SER GE- RENCIADO?}

Gestão do conhecimento é uma expressão que tem motivado debates na academia e no mundo organizacional. Um dos importantes autores da ciência da informação, Tom Wilson, afirma que dados e informação podem ser gerenciados; recursos informacionais podem ser gerenciados, mas conhecimento [isto é, o que sabemos] nunca pode ser gerenciado, exceto pelo próprio conhecedor e, mesmo assim, de forma imperfeita (WILSON, 2002). Esse mesmo ponto de vista é defendido por outros autores, como Krogh, Ichizo e Nonaka (2001). Esses autores, no prefácio do seu livro, afirmam: "estamos absolutamente convencidos de que não se gerencia o conhecimento, apenas capacita-se para o conhecimento". Mais 
à frente, eles afirmam que o termo gestão implica controle de processos que talvez sejam intrinsecamente incontroláveis ou, pelo menos, que talvez sejam sufocados por um gerenciamento mais intenso. Esses autores concluem que os gerentes devem promover a criação de conhecimento, em vez de controlá-la Como forma de facilitar a criação do conhecimento na empresa os autores sugerem, então, alguns elementos "capacitadores", que são: a) instilar a visão do conhecimento, b) gerenciar as conversas, c) mobilizar os ativistas do conhecimento, d) criar o contexto adequado e e) globalizar o conhecimento local.

Observa-se, entretanto, que o questionamento levantado por Krogh, Ichizo e Nonaka diz respeito ao que significa "gestão". Afinal, o que são os elementos "capacitadores" acima indicados, senão processos gerenciais? Podem não ser processos "intensos", ou que possam vir a "sufocar" a criação do conhecimento, mas nem por isto deixam de ser processos gerenciais, no sentido de que são concebidos e planejados, executados e, posteriormente, avaliados. Se formos limitar os processos gerenciais àqueles "intensos" e "sufocantes", não poderíamos falar de gestão de recursos humanos, gestão de pessoas e de gestão de competências, para citarmos apenas alguns processos gerenciais.
Administrar ou gerenciar o conhecimento não implica exercer controle direto sobre o conhecimento pessoal. Significa, sim, o planejamento e controle do contexto, ou $b^{1}$; enfim, das situações nas quais esse conhecimento possa ser produzido, registrado, organizado, compartilhado, disseminado e utilizado de forma a possibilitar melhores decisões, melhor acompanhamento de eventos e tendências externas e uma contínua adaptação da empresa a condições sempre mutáveis e desafiadoras do ambiente onde a organização atua.

\section{A GESTÃO DO CONHECIMENTO É MAIS UM MODISMO GERENCIAL?}

Ou aspecto da polêmica a respeito da gestão do conhecimento é se ela não passa de um modismo gerencial, assim como reengenharia, qualidade total e tantos outros. Para investigar essa questão, Ponzi e Koenig (2002) usaram os arquivos do Science Citation Index, Social Science Citation Index e $A B I$ Inform, e registraram o número de vezes em que a expressão knowledge management apareceu no título, no sumário ou nas palavras chaves das publicações regis-

\footnotetext{
${ }^{1}$ Para Nonaka e Kono (1998, p. 40), ba "pode ser concebido como um espaço compartilhado para relacionamentos emergentes". Esse espaço pode ser físico (por exemplo, escritórios), virtual (por exemplo, e-mail, teleconferências) ou mental (experiências compartilhadas, idéias, ideais) ou qualquer combinação destes.
} 
tradas nessas bases. Os resultados desse estudo podem ser sintetizados na Figura 1.

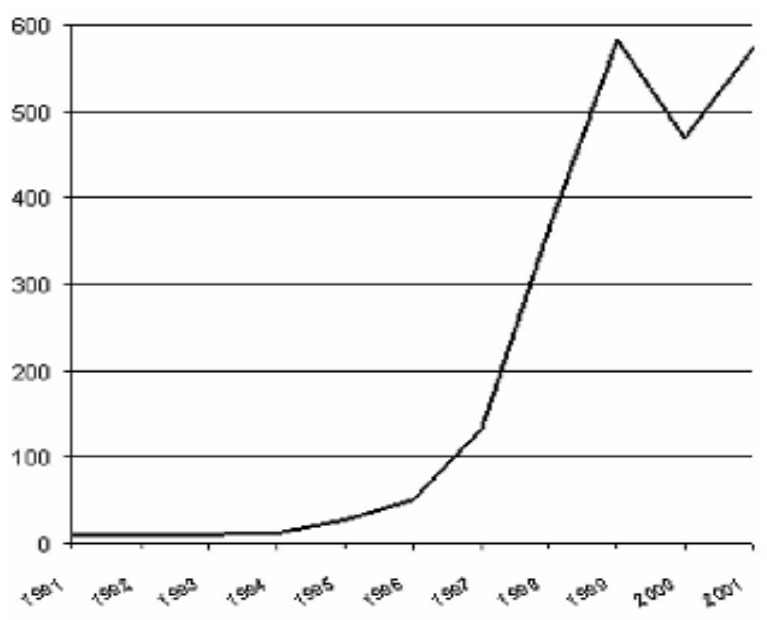

Figura 1 - Gestão do conhecimento, 1991-2001 Fonte: Ponzi e Koenig, 2002

Os dados da Figura 1 evidenciam um grande crescimento das publicações a respeito da gestão do conhecimento no período 1996 a 2001. E, com base na estimativa de que os modismos no campo da administração duram aproximadamente cinco anos, os autores sugerem que a gestão do conhecimento sobreviveu a esse teste. Para eles, à medida que a gestão do conhecimento tornar-se, de fato, um elemento permanente da atenção gerencial, ela continuará a evoluir e se transformará em um conceito mais claro e de fácil entendimento.

A pesquisa de Ponzi e Koenig (2002) evidencia, também, que os artigos passaram, ao longo do tempo, a ser publicados em periódicos das mais diversas áreas do conhecimento. Conforme a estimativa des- ses autores em 1996 os artigos apareciam apenas em publicações das áreas de ciência da computação, administração e negócios mas, a partir de 1999, eles passaram a ser encontrados também nas áreas de ciência da informação, biblioteconomia, engenharia, psicologia, energia, ciências sociais, pesquisa operacional e planejamento e desenvolvimento. Esses dados revelam um aspecto adicional, que é o fato de a gestão do conhecimento ter-se tornado progressivamente um campo interdisciplinar.

Acredita-se que, como qualquer fenômeno de mídia, os termos utilizados nas publicações científicas e profissionais experimentem o que poderia ser chamado de "fadiga terminológica". Isto significa que, ao longo do tempo, as pessoas passem a prestar menos atenção a termos que se repetem com muita freqüência. Isto não implica, no entanto, que o conceito se torne menos importante. Tomemos, por exemplo, o caso da Administração por Objetivos (APO) e da Qualidade Total (QT). A APO, introduzida por Peter Drucker na década de 1950, preconiza a idéia de que uma organização deva estabelecer objetivos para cada um de seus membros e setores e que esses objetivos levem em conta as metas organizacionais. Sob esse aspecto, cada funcionário ou gerente deveria ter seus próprios objetivos estabelecidos em termos de níveis de desem- 
penho, de horizontes temporais, etc., e esse processo seria conduzido de maneira participativa na empresa como um todo. Da mesma forma, o movimento da qualidade total (QT) defendia a necessidade de se desenvolver, dentro das organizações, uma constante preocupação com a qualidade em todos os processos organizacionais. Tanto a APO quanto a QT focalizam fenômenos e processos organizacionais e gerenciais que são e sempre serão essenciais em qualquer época. $O$ fato deles não serem populares como antigamente o foram não significa que seus princípios tenham se tornado irrelevantes. Pelo contrário; pode-se mesmo argumentar que, exatamente devido à sua importância, esses princípios foram sendo gradativamente incorporados ao conhecimento gerencial "convencional" e, em decorrência disto, tornam-se "invisíveis". De fato, conforme Gibson, Tesone e Blackwell (2003), modismos gerenciais tendem a ser incorporados em práticas gerenciais convencionais - tal como ocorreu com a APO - ou se tornarem embriões de novas ondas, como é o caso do movimento da qualidade total e dos círculos de qualidade, que evoluíram em direção das equipes auto-administradas e do "empoderamento" (empowerment) dos funcionários.

A hibridação interdisciplinar da gestão do conhecimento detectada por Ponzi e Koenig (2002) aponta para uma tendência de que a expressão "gestão do conhecimento" esteja sendo progressivamente substituída por temas a ela associados, tais como capital intelectual, ativos intangíveis, ou sendo combinados com conceitos que refletem aspectos mais especializados, tais como compartilhamento do conhecimento, redes sociais e outros. Esta é uma questão merecedora de futuros estudos, em especial por parte de pesquisadores do campo da ciência da informação.

Ao mesmo tempo em que compartiIham diversos elementos comuns, a gestão da informação e a gestão do conhecimento são diferentes sob diversos aspectos. Essas disciplinas, embora compartilhando importantes aspectos comuns, possuem suas particularidades. Na próxima seção, será feita uma tentativa de se estabelecer uma comparação entre essas disciplinas. 
5 GESTÃO DA INFORMAÇÃO E GESTÃO DO CONHECIMENTO - UMA COMPARAÇÃO

Como se pode constatar a partir das idéias acima apresentadas, a gestão da informação e a gestão do conhecimento focalizam aspectos complementares de dois importantes fenômenos organizacionais. Enquanto a GI focaliza a informação ou o conhecimento registrado, a GC destaca o co- nhecimento pessoal, muitas vezes tácito, e que, para ser efetivamente utilizado, antes precisa ser descoberto e socializado.

No Quadro 1, são apresentadas algumas diferenças entre a gestão da informação e a gestão do conhecimento.

\begin{tabular}{l|l|l}
\hline Critério & Gestão da informação & Gestão do conhecimento \\
\hline Fenômenos centrais & $\begin{array}{l}\text { Informação ou conhecimen- } \\
\text { to explícito }\end{array}$ & $\begin{array}{l}\text { Conhecimento tácito, competências pes- } \\
\text { soais }\end{array}$ \\
\hline Visibilidade dos fenômenos & Baixa & Muito baixa \\
\hline Processos críticos & $\begin{array}{l}\text { Organização e tratamento } \\
\text { da informação }\end{array}$ & $\begin{array}{l}\text { Descoberta e compartilhamento do co- } \\
\text { nhecimento }\end{array}$ \\
\hline $\begin{array}{l}\text { Nível de centralidade para a } \\
\text { gestão estratégica }\end{array}$ & Mediana & Alta \\
\hline $\begin{array}{l}\text { Influência da cultura organi- } \\
\text { zacional sobre processos e } \\
\text { resultados }\end{array}$ & Mediana & Alta \\
\hline $\begin{array}{l}\text { Possibilidade de gerencia- } \\
\text { mento }\end{array}$ & Baixa ou mediana & Baixa ou muito baixa \\
\hline $\begin{array}{l}\text { Outros conceitos relaciona- } \\
\text { dos }\end{array}$ & $\begin{array}{l}\text { Sistemas de informação, } \\
\text { gestão eletrônica de docu- } \\
\text { mentos }\end{array}$ & $\begin{array}{l}\text { Capital intelectual, ativos intangíveis, } \\
\text { aprendizagem organizacional }\end{array}$ \\
\hline $\begin{array}{l}\text { Principais campos disciplina- } \\
\text { res envolvidos }\end{array}$ & $\begin{array}{l}\text { Ciência da computação, } \\
\text { ciência da informação, bi- } \\
\text { blioteconomia, arquivologia }\end{array}$ & Administração, ciência da informação \\
\hline
\end{tabular}

Quadro 1 - Uma comparação entre a gestão da informação e a gestão do conhecimento

Em primeiro lugar, destaca-se o fato de que o fenômeno central da gestão da informação é a informação ou o conhecimento explícito. Ou seja, a GI lida com o universo de documentos, dos mais diversos tipos, os quais são produzidos, armazenados e utilizados em um contexto organizacional. Por outro lado, o fenômeno central da gestão do conhecimento é o conhecimento pessoal, aquele que se encontra na cabeça das pessoas e que muitas vezes não é registrado 
nem compartilhado. A conexão entre informação e conhecimento é evidenciada no modelo conhecido como espiral do conhecimento, desenvolvido por Nonaka e Takeuchi (1997). De acordo com esse modelo, o conhecimento, uma vez externalizado por uma pessoa, pode ser transformado em informação e esta, quando internalizada por outra, transforma-se em conhecimento.

Tanto a gestão da informação quanto a gestão do conhecimento lidam com processos complexos, elusivos e de difícil observação. Os documentos podem ser observados, assim como o comportamento das pessoas que refletem o seu conhecimento. No entanto, os fenômenos informação e conhecimento, em si, são praticamente invisíveis em contextos organizacionais, e isto constitui um grande paradoxo.

As organizações podem ser enfocadas sob diversos aspectos (MORGAN, 1996). A área de recursos humanos, por exemplo, prioriza, em seu olhar, aspectos relacionados com as pessoas, suas competências, desempenho, motivações, dentre outros. Sob o ângulo das finanças e da contabilidade, ganham destaque os fluxos e estoques monetários; sob uma perspectiva estrutural, a organização se revela como um conjunto de setores ou subunidades relacionadas entre si. A perspectiva informacional pode ser considerada uma perspectiva de nível superior, uma meta perspectiva, na medida em que uma organização é e funciona como uma rede de informação e de conhecimento. $E$, como a informação e o conhecimento se confundem com todas as demais perspectivas da organização, eles se tornam invisíveis. É como o ar que respiramos; como ele está em toda parte, ele se torna invisível.

A determinação de necessidades e a aferição do uso da informação constituem grandes desafios para a gestão. No entanto, uma vez que os documentos possam ser coletados, produzidos, organizados, manipulados e distribuídos, considera-se que a informação seja um fenômeno de maior visibilidade do que o conhecimento que, essencialmente, é algo que existe na mente das pessoas. As chamadas "paginas amarelas corporativas" é uma iniciativa, de gestão da informação, que tem como objetivo possibilitar a identificação e localização de conhecimentos e competências possuídos pelos membros de uma organização. Esta idéia tem sua origem na técnica de Infomapping, ou mapeamento informacional, que foi desenvolvida por Horton Junior na década de 1980. Por meio desses guias, é possível saber quem sabe o quê dentro de uma empresa. Neste caso, o guia remete o usuário a uma pessoa e não a um documento. Tratase, portanto, de uma aplicação, destinada 
essencialmente a aproximar uma pessoa que deseja um conhecimento de outra que possui esse conhecimento, e que tanto pode ser considerada uma prática de gestão de informação quanto de gestão do conhecimento.

Uma vez que as organizações contemporâneas se caracterizam pela contínua produção, processamento e uso da informação, pode-se considerar que os processos críticos da gestão da informação sejam a organização e o tratamento da informação. Com efeito, o crescente volume de informações que as empresas precisam processar atualmente evidencia a importância de um sistema que seja capaz de representar o conteúdo informacional dos documentos, de forma a possibilitar a sua futura recuperação. Por outro lado, descobrir onde se encontra o conhecimento, bem como o seu compartiIhamento, constituem aspectos essenciais para a gestão do conhecimento.

O compartilhamento do conhecimento pessoal é um processo que sofre forte influência da cultura organizacional (ARDICHVILI et al., 2006; McDERMOTT; O’DELL, 2001) e é considerado, por muitos, como um dos aspectos que mais contribuem para a sua competitividade (DAVENPORT; PRUSAK, 1998). A importância do conhecimento na elaboração de estratégias empresariais tem sido registrada por diversos autores (APRIL, 2002; DREW, 1999; LIEBESKIND, 1996; ZACK, 1999). Da mesma forma, o alinhamento estratégico dos sistemas de informação organizacionais é tema recorrente na literatura (BURN; SZETO, 2000; HENDERSON; VENKATRAMAN, 1999). Embora tanto a informação quanto sejam aspectos importantes do ponto de vista da estratégia organizacional, acredita-se que o conhecimento organizacional, por ser único e peculiar, possa ser considerado um elemento de maior centralidade para a gestão estratégica de uma organização do que a gestão da informação.

A cultura de uma organização, entendida como um conjunto de pressupostos e valores compartilhado por um determinado grupo, exerce impactos tanto sobre a gestão da informação quanto sobre a gestão do conhecimento. Conforme Birkinshaw (2001, p. 12), "modificar o sistema de gestão do conhecimento de uma empresa não é diferente de mudar a sua cultura - envolve mudanças fundamentais no comportamento das pessoas, e tipicamente demora muitos anos para acontecer". Para Curry e Moore (2003, p. 94), uma cultura informacional é aquela na qual se reconhece "o valor e a utilidade da informação para o alcance do sucesso operacional e estratégico". 
Os efeitos da cultura organizacional sobre os sistemas de informação organizacionais foram analisados por Claver et al. (2001). Esses autores estabelecem distinções entre cultura informática e cultura informacional. Em síntese, enquanto a primeira valoriza a importância da TI para a empresa, a segunda é mais abrangente e complexa por também incorporar as pessoas, a informação e os dados. A implementação da TI sob uma cultura de informática é conduzida apenas pelo pessoal técnico; os usuários são desconsiderados e o envolvimento da alta administração no processo é restrito. A distinção feita por esses autores reforça a idéia, aqui proposta, de que cultura organizacional exerce maiores impactos sobre a gestão do conhecimento do que sobre a gestão da informação.

Se levarmos em conta que os ambientes de uso da informação e do conhecimento são cada vez mais dinâmicos e mutáveis, chega-se à conclusão de que não há uma verdadeira resolução para a GIC. Ou seja, o gerenciamento da informação e do conhecimento em contextos organizacionais possui algumas das características do que Rittel e Webber (1973) chamaram de problemas malvados (wicked $)^{2}$, ao invés de mansos ou adestrados (tame). Em primeiro lugar, não existem formulações definitivas para esse tipo de problema, bem como não existem regras para a sua conclusão. Da mesma forma, também não existe um teste definitivo para se avaliar a solução de um problema malvado. Além do mais, tais tipos de problemas, além de serem essencialmente únicos, não têm um conjunto finito de soluções possíveis. Ou seja, tanto a GI quanto a GC são problemas difíceis de ser gerenciados, embora a GC, por lidar com fenômenos de menor visibilidade e envolver aspectos íntimos das pessoas, é mais difícil ainda de ser administrada.

Não se pretende aqui sugerir a impossibilidade de se obter sucesso na implantação e gerenciamento de programas de gestão da informação e do conhecimento e sim que esses programas dependem da criação e cultivo de ambientes verdadeiramente favoráveis ao seu desenvolvimento. Dentre essas condições, pode ser destacado fomento de uma cultura informacional favorável, o que envolve o apoio e o incentivo ao compartilhamento da informação, a administração do excesso e da sobrecarga informacional, bem como o controle de múltiplos significados de conceitos e termos que ca-

\footnotetext{
${ }^{2}$ Wicked significa algo moralmente mau, pecaminoso, terrível, repelente, revoltante ou deplorável. Não existe uma palavra correspondente em português,

sendo que malvado é a que mais se aproxima do sentido originalmente proposto por Rittel e Webber.
} 
racterizam contextos organizacionais complexos (DAVENPORT, 1997).

Um fator crítico para o sucesso na introdução de programas de gestão da informação em organizações é o senso de oportunidade dos profissionais envolvidos. Ou seja, a riqueza e complexidade dos ambientes informacionais das organizações contemporâneas constituem, ao mesmo tempo, desafios e oportunidades para esses profissionais envolvidos.

As próprias origens e a evolução da gestão da informação e do conhecimento destacam os aspectos interdisciplinares dessas disciplinas. Elas se relacionam, no entanto, com diferentes conceitos. Por exemplo, enquanto a gestão da informação se associa intimamente com a gestão eletrônica de documentos e os sistemas de informação, a gestão do conhecimento relaciona-se com a gestão do capital intelectual e de ativos intangíveis, bem como a aprendizagem organizacional. Nesse caso, fica evidente a influência de disciplinas relacionadas à administração; das finanças, no caso do capital intelectual e do comportamento organizacional e da gestão estratégica no caso da aprendizagem organizacional. Por outro lado, a GI mantém estreitas conexões disciplinares com a ciência da informação, a ciência da computação, a biblioteconomia e a arqui- vologia. Acredita-se que essas trocas interdisciplinares se intensifiquem no futuro. Um possível indicador dessa tendência é o número de escolas e departamentos da área de ciência da informação e/ ou biblioteconomia que se associam a departamentos de administração, computação, comunicação ou educação. O perfil do corpo docente desses programas também tem se tornado multidisciplinar, o que contribui para aumentar as interfaces entre as disciplinas.

\section{GESTÃO DA INFORMAÇÃO E GESTÃO DO CONHECIMENTO - UMA VISÃO IN- TEGRADA}

A gestão da informação e a gestão do conhecimento possuem fortes conexões intelectuais. Ao longo do tempo, essas conexões têm se estreitado de muitas formas. Por exemplo, diversos periódicos científicos estabelecem conexões entre a ciência da informação, a administração e a computação, em especial no que se refere aos sistemas de informação.

No campo das instituições acadêmicas, nota-se também a existência de um número crescente de departamentos que integram essas três áreas. Os programas e ofertas de disciplinas também refletem essa aproximação entre os campos. A Figura 2, constitui uma tentativa de representar conceitos e funções, oriundos do campo da administra- 
ção, da computação e da ciência da informação, que podem ser considerados relevantes para a gestão da informação e do conhecimento. Do território da administra- ção, destacam-se as disciplinas de recursos humanos, estratégia empresarial e finanças.

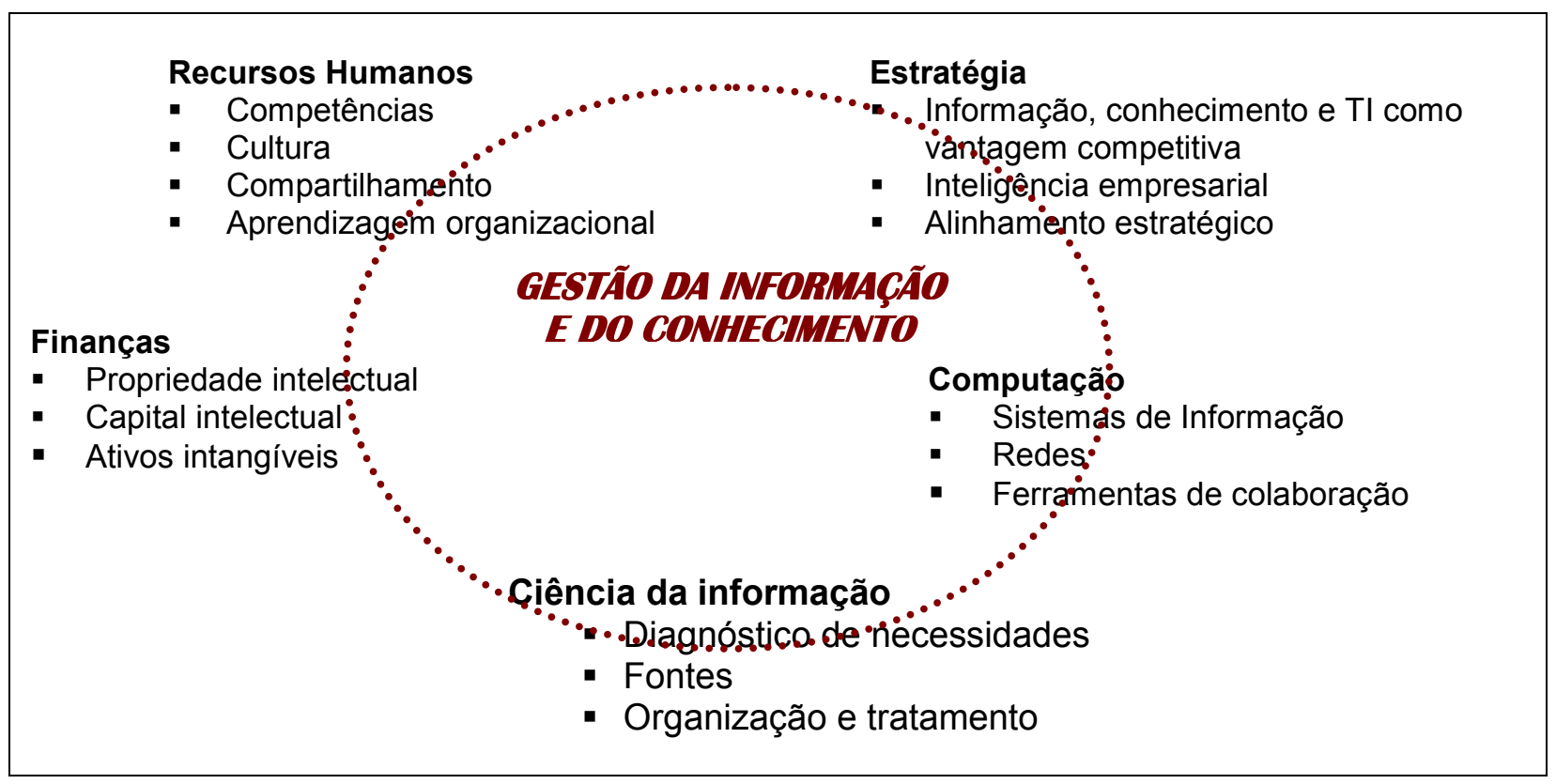

Figura 2 - Uma perspectiva integradora da gestão da informação e do conhecimento

A gestão do conhecimento se associa à gestão de recursos humanos uma vez que ela envolve o gerenciamento de competências e talentos pessoais. Assim, a sua implementação demanda o desenvolvimento de uma cultura organizacional receptiva, na qual se valoriza o compartilhamento do conhecimento. Por último, a gestão do conhecimento contribui decisivamente para que a organização se adapte às condições mutáveis do seu ambiente por intermédio da aprendizagem organizacional. Esse processo de adaptação é objetivo também da gestão estratégica. Neste caso, destacam-se os conceitos de alinhamento estratégico dos sistemas e recursos de informação com os objetivos e metas da organização. Outro aspecto central, neste sentido, é a inteligência competitiva, também conhecida como inteligência empresarial, que pode ser concebida como uma série de processos por meio dos quais informações relevantes a respeito do ambiente empresarial externo são obtidas e utilizadas como insumo ao processo decisório estratégico (AGUILAR, 1967).

Na medida em que envolvem a necessidade, busca e uso da informação, as ativi- 
dades de inteligência competitiva em uma empresa constituem um processo informacional por excelência. Conceitualmente, ela tem início com um diagnóstico de necessidades de informação por parte da cúpula organizacional, o qual conduz à aquisição da informação que, uma vez organizada e armazenada, é distribuída para seus usuários na forma de produtos e serviços de informação, os quais serão utilizados na interpretação de tendências e eventos do meio ambiente externo, no processo decisório em nível estratégico e nas ações voltadas para promover a adaptação da organização a novas condições e exigências do ambiente empresarial (CHOO, 2002).

A perspectiva das finanças e da contabilidade na gestão do conhecimento se manifesta por meio da crescente preocupação das empresas no sentido de gerenciarem seu capital intelectual e seus ativos intangíveis. Enquanto os autores do campo da contabilidade já têm se ocupado com a contabilização de recursos humanos há cerca de três décadas, foi por meio do trabalho de autores como Stewart $(1998,2002)$ que a expressão capital intelectual tornou-se popular. Esse autor desenvolve o conceito de capital intelectual como sendo constituído de três elementos. O capital humano envolve o talento, experiência e a capacidade de inovação das pessoas. O capital estrutural, por sua vez, é a soma dos ativos tangíveis de uma empresa, incluindo ativos financeiros, fábricas, máquinas e equipamentos, bem como a infra-estrutura física de distribuição e vendas. Para Petty e Guthrie (2000), devem ser incluídos no capital estrutural os sistemas de informação, as redes de distribuição e as cadeias de suprimento. O capital do cliente, por sua vez, consiste no conteúdo das informações sobre a clientela, armazenadas em bases de dados, bem como seu grau de satisfação e de lealdade à companhia. Observa-se, portanto, que o conceito de capital intelectual relaciona-se tanto com a gestão da informação, quando ele referese a informações registradas, quanto com a gestão do conhecimento, quando ele diz respeito ao valor contido no talento e na experiência.

A ciência da computação, como já se demonstrou, possui estreitas conexões tanto com a gestão da informação quanto com a gestão do conhecimento. Em especial, destacam-se, neste sentido, os sistemas de informação, as redes e as ferramentas de colaboração. Atualmente, observa-se o intenso desenvolvimento de sistemas que possibilitam a colaboração entre pessoas. Esse é, sem dúvida, um fenômeno que pode aprofundar, e mesmo eliminar, as já tênues distinções entre a gestão da informação e a do conhecimento. 


\section{CONCLUSÕES}

Este artigo procurou demonstrar a importância de se enxergar a informação e o conhecimento como fenômenos indissociáveis e complementares da vida organizacional. O conhecimento, uma vez registrado, transforma-se em informação e esta, uma vez internalizada, torna-se conhecimento. Esses processos, na realidade, sempre constituíram a essência de qualquer organização criada pelo homem moderno. A rigor, o que constitui novidade é a escala em que essa troca ocorre em decorrência das incessantes inovações tecnológicas no campo da computação e das telecomunicações.

Levando-se em conta esse contexto de profundas transformações, salientou-se a necessidade de uma atenção focalizada e um gerenciamento especializado sobre fenômenos e processos relacionados à informação e ao conhecimento nas organizações. E, para que esse gerenciamento seja efetivo, é necessário o desenvolvimento de uma forma de olhar a organização sob o prisma da informação e do conhecimento. Este tipo de olhar irá permitir a visão das pessoas tanto como usuárias quanto como produtoras de informação, detectar repositórios de informação que talvez passassem desapercebidos, bem como visualizar fontes e fluxos externos e internos de informação.

Como conseqüência da visão holística da informação, aspecto salientado por Davenport (1997), destaca-se a importância de equipes multidisciplinares no trato com a informação e o conhecimento. Acredita-se que apenas por meio da formação de tais equipes, formadas por especialistas em computação, comunicação, bem como bibliotecários, arquivistas, administradores e outros profissionais, será possível o desenvolvimento de uma abordagem condizente com as exigências das modernas formas organizacionais.

Tanto para administradores quanto outros profissionais, é importante enxergar para além dos termos, que podem mudar ao longo do tempo. A polêmica a respeito da tríade dado - informação - conhecimento é antiga. E, em uma empresa, esses fenômenos devem ser inseridos em contextos mais amplos e a questão do uso e da identificação de necessidades de informação tornamse aspectos fundamentais. Mesmo o conhecimento, considerado ingrediente essencial para o processo decisório organizacional, muitas vezes se distancia da ação organizacional (PFEFFER; SUTTON, 1999). 
Neste contexto, ganha importância a questão da competência informacional, conceito que pode se aplicar tanto a pessoas como a organizações. Trata-se, no caso, de saber utilizar a informação e o conhecimento de maneira efetiva. Ou seja, parafraseando Michael Polanyi, famoso pela expressão "sabemos mais do que podemos dizer", podemos dizer também que tanto as pessoas quanto as organizações "sabem mais do que conseguem colocar em prática." Descobrir, organizar, disseminar e utilizar esse conhecimento de maneira efetiva constitui o grande desafio da gestão da informação e do conhecimento.

\section{REFERÊNCIAS}

AGUILAR, F. J. Scanning the business environment. New York: Macmillan, 1967.

APRIL, K. Guidelines for developing a kstrategy. Journal of Knowledge Management, Bingley, v. 6, n. 5, p. 445-456, 2002.

ARDICHVILI, A. et al. Cultural influences on knowledge sharing through online communities of practice. Journal of Knowledge Management, Bingley, v. 10, n. 2, p. 94-107, 2006.

BERGERON, P. Information resources management. Annual Review of Information Science and Technology, White Plains, v. 31, p. 263-300, 1996.

BERRY, J. F.; COOK, C. M. Managing knowledge as a corporate resource. Wash- ington: Department of Defense, 1976. Disponível em:

$<$ http://oai.dtic.mil/oai/oai?verb=getRecord\& metadataPrefix=html\&identifier=ADA029891>. Acesso em: 23 mar. 2008.

BIRKINSHAW, J. Why is knowledge management so difficult? Business Strategy Review, Oxford, v. 12, n. 1, p. 11-18, 2001.

BRASIL. Ministério do Desenvolvimento Indústria e Comércio Exterior. Investimentos em TI no Brasil devem responder por 2,2\% do PIB em 2007. Disponível em: < $<$ http://www.telecentros.desenvolvimento.go $\mathrm{v}$.br/sitio/destaques/destaque.php?sq noticia =66>. Acesso em: 25 ago. 2007.

BURN, J. M., SZETO, C. A comparison of the views of business and IT management of success factors for strategic alignment. Information \& Management, Amsterdam, v. 37 , n. 4, p. 197-216, 2000.

BUSH, V. As we may think. The Atlantic Monthly, Boston, v. 176, n. 1, p. 101-108, July 1945.

$\mathrm{CHOO}, \mathrm{C} . \mathrm{W}$. Information management for the intelligent organization. 3. ed. Medford: American Society for Information Science and Technology, 2002.

CLAVER, E. et al. The performance of information systems through organization culture. Information Technology \& People, Bradford, v. 14 , n. 3, p. 247-260, 2001.

CURRY, A.; MOORE, C. Assessing information culture: an exploratory model. International Journal of Information Management, Guildford, v. 23, n. 2, p. 91-110, apr. 2003.

DAVENPORT, E.; CRONIN, B. Knowledge management: semantic drift or conceptual shift?. Annual Meeting of the Association for Library and Information Science Education, San Antonio, Jan. 2000. Disponível em: 
$<$ http://www.alise.org/nondiscuss/conf00 Da venport-Cronin paper.htm>. Acesso em: 23 mar. 2008.

DAVENPORT, T. H. Ecologia da informação: por que só a tecnologia não basta para o sucesso na era da informação. São Paulo: Futura, 1997.

DAVENPORT, T. H.; PRUSAK, L. Conhecimento empresarial: como as organizações gerenciam o seu capital intelectual. 6. ed. Rio de Janeiro: Campus, 1998.

DREW, S. Building knowledge management into strategy: making sense of a new perspective. Long Range Planning, London, $v$. 32, n. 1, p. 130-136, mar. 1999.

DRUCKER, P. F. The age of discontinuity: guidelines to our changing society. New York: Harper and Row, 1969.

GEHANI, R. R. Chester Barnard's 'executive' and the knowledge-based firm. Management Decision, York, v. 40, n. 10, p. 980-991, 2002.

GIBSON, J. W.; TESONE, D. V.; BLACKWELL, C. W. Management fads: here yesterday, gone today? S.A.M. Advanced Management Journal, Cincinnati, v. 68, n. 3, p. 12-17, 2003.

GRANT, R. M. Toward a knowledge-based theory of the firm. Strategic management Journal, Sussex, v.17, Special Issue, p. 109122, 1996.

HARRIS, R. G. The knowledge-based economy: intellectual origins and new economic perspectives. International Journal of Management Reviews, Oxford, v. 3, n. 1, p. 2140, Mar. 2001.

HAYEK, F. A. The use of knowledge in society. The American Economic Review, Nashville, v. 35, n. 4, p. 519-530, Sep. 1945.
HENDERSON, J. C.; VENKATRAMAN, N. Strategic alignment: leveraging information technology for transforming organizations. IBM Systems Journal, Armonk, v. 38, n. 2, p. 472-484, 1999.

HENRY, N. Knowledge management: a new concern for public administration. Public Administration Review, Washington, v. 34, n. 3, p. 189-196, may/june 1974.

HORTON JUNIOR, F. W. Resource management: principles and practices. In: Information resources management: concepts and cases. Cleveland: Association for Systems Management, 1979. p. 29-51.

IDG NOW. Investimentos em TI chegarão a US\$ 1,55 tri em 2007, prevê Forrester. 2006. Disponível em: $<$ http://idgnow.uol.com.br/mercado/2006/11/ 22/idgnoticia.2006-11-22.8409294082>. Acesso em: 25 ago. 2007.

KROGH, G.; ICHIJO, K.; NONAKA, I. Facilitando a criação de conhecimento: reinventando a empresa com o poder da criação contínua. Rio de Janeiro: Campus, 2001.

LIEBESKIND, J. P. Knowledge, strategy, and the theory of the firm. Strategic management Journal, Sussex, v. 17, Special Issue, p. 93107, 1996.

McDERMOTT, R.; O’DELL, C. Overcoming cultural barriers to sharing knowledge. Journal of Knowledge Management, Bingley, v. 5, n. 1, p. 76-85, 2001.

MOKYR, J. The gifts of Athena: historical origins of the knowledge economy. Princeton: Princeton University Press, 2002.

MOREIRA, W. Os colégios invisíveis e a nova configuração da comunicação científica. Ciência da Informação, Brasília, v. 34, n. 1, p. 57-63, jan./abr. 2005. 
MORGAN, G. Imagens da organização. São Paulo: Atlas, 1996.

NONAKA, I., TAKEUCHI, H. Criação de conhecimento na empresa: como as empresas japonesas geram a dinâmica da inovação. Rio de Janeiro: Campus, 1997.

NONAKA, I.; KONNO, N. The concept of "ba": building a foundation for knowledge creation. California Management Review, Berkeley, v. 40, n. 3, p. 40-54, 1998.

PETTY, R.; GUTHRIE, J. Intellectual capital literature review: measurement, reporting and management. Journal of Intellectual Capital, Bradford, v. 1, n. 2, p. 1469-1930, 2000.

PFEFFER, J.; SUTTON, R. I. Knowing "what" to do is not enough: turning knowledge into action. California Management Review, Berkeley, v. 42, n. 1, p. 83-104, 1999.

PONZI, L., J.; KOENIG, M. Knowledge management: another management fad? Information Research, Lund, v. 8, n. 1, Oct. 2002.

POWELL, W. W.; SNELLMAN, K. The knowledge economy. Annual Review of Sociology, Palo Alto, v. 30, n. 1, p. 199-220, 2004.

PRUSAK, L. Where did knowledge management came from? IBM Systems Journal, Armonk, v. 40, n. 4, p. 1002-1007, 2001.

RAYWARD, W. B. The case of Paul Otlet, pioneer of information science, internationalist, visionary: reflections on biography. Journal of Librarianship and Information Science, London, v. 23, n. 23, p. 135-145, Sep. 1991.

RITTEL, H. W. J.; WEBBER, M. M. Dilemmas in a general theory of planning. Policy Sciences, Dordrecht, v. 4, n. 2, p. 155-169, 1973.
SARACEVIC, T. Information Science. Journal of the American Society for Information Science, Washington, v. 50, n. 12, p. 10511063, Oct. 1999.

SAVIC, D. Evolution of information resource management. Journal of Librarianship and Information Science, London, v. 24, n. 3, p. 127-138, Sep.1992.

SHIN, N. The impact of information technology on financial performance: the importance of strategic choice. European Journal of Information Systems, Birmingham, v. 10, n. 4, p. 39-53, Dec. 2001.

STEWART, T. A. A riqueza do conhecimento: o capital intelectual e a organização do Século XXI. Rio de Janeiro: Campus, 2002.

STEWART, T. A. Capital intelectual: a nova vantagem competitiva das empresas. Rio de Janeiro: Campus, 1998.

WILSON, T. D. The nonsense of 'knowledge management'. Information Research, Lund, v. 8, n. 1, Oct. 2002.

ZACK, M. H. Developing a knowledge strategy. California Management Review, Berkeley, v. 41, n. 3, p. 125-145, 1999.

\section{Title}

Information and Knowledge Management: origins, controversial arguments and perspectives

\begin{abstract}
s
The article presents and discusses the concepts and the importance of information and knowledge in a business context. It compares the information and knowledge management, and some aspects related to these disciplines origin and evolution. It evidences the use of information
\end{abstract}


technology and its value for information and knowledge management. It discusses the features that give basis to knowledge management and emphasizes that more than a buzzword it is an issue recognized by research and scientific publications. It concludes that information and knowledge figure as an inseparable and a complementary organizational phenomenon, and that the technological innovations in Computer Science and telecommunications contribute to information and knowledge sharing.

\section{Keywords}

Information Management; Knowledge Management; Information Technology; Organizational Knowledge.

\section{Titulo}

Gestión de Información y del Conocimiento: origen, polémicas y perspectivas

\section{Resumen}

El artículo presenta y discute los conceptos y la importancia de la información y del conocimiento en un contexto empresarial. Compara la gestión de información y la gestión del conocimiento, y los aspectos relacionados con el origen y la evolución de estas disciplinas. Se destaca el uso de la tecnología de la información y su valor en la gestión de información y el conocimiento. En él se abordan las complejidades de mantener los preceptos de la gestión del conocimiento y destaca que a más de una moda, es un tema que está consolidando en investigaciones y publicaciones científicas. Concluye que la información y el conocimiento son inseparables y complementarios y que las imnovaciones tecnológicas en las áreas de computación y de las telecomunicaciones contribuyen a la difusión de la información y el conocimiento en las organizaciones.

\section{Palabras Clave}

Gestión de Información; Gestión del Conocimiento; Tecnología de la Información; Conocimiento dentro de las Organizaciones.

Recebido em: 14.05.2008

Aceito em: 20.10.2008 